Jussara Cruz de Brito ${ }^{1}$

Mary Yale Neves ${ }^{2}$

Simone Santos Oliveira ${ }^{3}$

Lucia Rotenberg ${ }^{4}$

\section{Saúde, subjetividade e trabalho: o enfoque clínico e de gênero}

\author{
Health, subjectivity and work: the clinical and gender approaches
}

${ }^{1}$ Engenheira, Pós-doutora em Ergologia. Pesquisadora da Escola Nacional de Saúde Pública Sérgio Arouca, Fiocruz, Rio de Janeiro, RJ, Brasil.

2 Psicóloga, Pós-doutora em Saúde Coletiva, Docente do Instituto de Ciências Humanas e Filosofia, Universidade Federal Fluminense, Niterói, RJ, Brasil.

${ }^{3}$ Graduada em Ciências Sociais, Doutora em Saúde Pública, Pesquisadora da Escola Nacional de Saúde Pública Sérgio Arouca, Fiocruz, Rio de janeiro, RJ, Brasil.

${ }^{4}$ Bióloga, Doutora em Psicologia. Pesquisadora do Laboratório de Educação em Ambiente e Saúde, Instituto Oswaldo Cruz, Fiocruz, Rio de Janeiro, RJ, Brasil.

O presente trabalho foi elaborado no âmbito do acordo de cooperação entre a Fundação Oswaldo Cruz e o Centre National de Recherche Scientifique, Centre de Recherches Sociologiques et Politiques de Paris, Genre Travail Mobilités (CNRS) e durante a vigência de apoio do CNPqà Jussara Cruz de Brito e Lúcia Rotenberg.

Contato:

Jussara Cruz de Brito

Centro de Estudos da Saúde do TrabaIhador e Ecologia Humana, Escola Nacional de Saúde Pública (ENSP/Fiocruz)

Rua Leopoldo Bulhões, 1480, Rio de Janeiro-RJ, Brasil.

CEP 21041-210

E-mail:

jussara@ensp.fiocruz.br

Recebido: 18/03/2012

Revisado: 23/08/2012

Aprovado: 14/09/2012

\section{Resumo}

Este trabalho visou tratar a relação entre saúde, subjetividade e trabalho a partir das contribuições das Clínicas do Trabalho - a Ergonomia da Atividade, a Clínica da Atividade, a Psicodinâmica do Trabalho - e da perspectiva Ergológica, que se aproximam da linhagem vitalista de Canguilhem, para apreender as relações saúde-trabalho, e do enfoque de gênero, analisado sob a perspectiva da apropriação do tempo de trabalho. Para tanto, recorremos ao levantamento do estado da arte acerca do tema e apresentamos resultados de estudos empíricos ligados a serviços (educação, saúde e telemarketing), inclusive análises decorrentes de investigações por nós realizadas, articulando com essas contribuições teóricas. Estas análises revelaram a importância do reconhecimento social do trabalho cuja natureza tem forte componente simbólico, possibilitando a construção do sentido no trabalho por parte dos sujeitos. As negociações cotidianas de afirmação da vida e, portanto, da saúde são perpassadas por relações sociais de classe e gênero. Os constrangimentos do tempo diferem segundo o gênero, traduzindo-se em diferenças na margem de tolerância ao meio. As contribuições revelaram que o movimento, a dinâmica e a mudança permanente, inerentes à vida (inclusive a de trabalho), são aspectos a serem contemplados nas análises das relações trabalho-saúde.

Palavras-chave: saúde do trabalhador; gênero; clínicas do trabalho; tempo; ergologia.

\begin{abstract}
In this article, we address the theme "health, subjectivity, and work" using two approaches. The first one follows close to Canguilhem's vitalist concept to understand the relationship between health and work, discussing the theoretical view of Work Clinics - the Ergonomics of Activity, the Work Clinic, the Psychodynamics of Work - and the Ergological perspective. The other approach focuses on gender analyzed from the perspective of the appropriation of working time. To accomplish this purpose, we searched the state of art on the theme and presented results of empirical studies related to services (education, health, and telemarketing), including analyses produced by our investigations, integrating them with these theoretical contributions. The analyses revealed the importance of the social recognition of work, which nature comprises a strong symbolic component that allows subjects to construct a meaning of work. Everyday negotiations of life, and consequently of health, are permeated by class and gender social relations. Time constraints differ according to gender, resulting in different levels of tolerance to the environment. The contributions showed that the movement, the dynamics and the constant changes inherent to life (and work) are aspects to be included in analyses of work-health relationships.
\end{abstract}

Keywords: workers' health; gender; work clinics; time; ergology. 


\section{Introdução}

A constituição do campo da Saúde Coletiva no Brasil pretende afirmar uma concepção dentro da Saúde Pública que recusa o monopólio dos discursos biológicos, incluindo as dimensões simbólica, ética e política na discussão sobre as condições de saúde das populações. Sua construção apoia-se na interdisciplinaridade e orienta-se pela busca de transformações, tanto no que tange à forma de organização dos serviços públicos de saúde, quanto no que se refere aos modos de vida das populações. O debate acerca das relações entre a saúde e o trabalho insere-se aí na medida em que se reconhece que os modos de vida são influenciados decisivamente pelos modos de trabalhar (AROUCA, 1975; BRITO, 2004; MINAYO-GOMES; LACAZ, 2005).

Este pensamento originou a proposta de uma área específica de investigação e intervenção da Saúde Coletiva denominada Saúde do Trabalhador. Esta nova área foi influenciada pelo movimento social italiano que eclodiu ao final da década de 1960, reunindo profissionais de saúde, sindicalistas e trabalhadores em torno da questão das condições de trabalho, conhecido como Modelo Operário Italiano de Luta pela Saúde (MOI). Uma das principais heranças deixadas pelo MOI no Brasil foi o entendimento de que os saberes dos trabalhadores são imprescindíveis para a análise e a intervenção que visem à saúde (ODDONE; RE; BRIANTI, 1981). Assim, a partir da década de 1970, um conjunto de investigações sobre a saúde dos trabalhadores assinala o caráter histórico e social do processo saúde-doença. Este passa a ser considerado um fenômeno biopsicossocial diretamente articulado com o processo de produção (LAURELL; NORIEGA, 1989).

Nesta direção, que enfatiza o caráter biopsicossocial da saúde, buscamos inicialmente neste artigo discutir algumas contribuições teóricas específicas à análise das relações saúde-trabalho. De um lado, trataremos das contribuições de abordagens, resguardadas as suas diferenças, que seguem ou se aproximam (explícita ou implicitamente) da linhagem vitalista de Canguilhem (1990b, 2001), desenvolvidas especialmente na França e identificadas como Clínicas do Trabalho, tais como a Ergonomia da Atividade (WISNER, 1994; GUÉRIN et al., 2001; DANIELLOU, 2004), a Clínica da Atividade (CLOT, 2006) e a Psicodinâmica do Trabalho de Dejours (LANCMAN; SZNELWAR, 2004), operadas sob a perspectiva ergológica (SCHWARTZ; DURIVE, 2010). Por outro lado, lançaremos mão dos aportes teóricos sobre as relações de gênero (HIRATA; KERGOAT, 2003; BRITO, 1999), incorporando também os estudos que tratam da dimensão temporal da vida cotidiana (ELIAS, 1998; ROTENBERG et al.,
2012). A nosso ver, ainda que as Clínicas do Trabalho tenham sido gestadas em um contexto distinto do que originou a área da Saúde do Trabalhador, elas são bastante valiosas para a compreensão das complexas relações saúde-trabalho, considerando que estas envolvem simultaneamente o biológico, o psicológico e o social com suas instâncias ideológicas, econômicas e político-jurídicas. As Clínicas do Trabalho têm origem em pesquisas e ações voltadas à transformação do trabalho e ao maior protagonismo dos trabalhadores no modo de lidar com as adversidades. Quanto aos estudos acerca das relações de gênero, esses nos apontam processos históricos que levam a inserções e modos de trabalhar diferenciados de homens e mulheres nos processos de trabalho, a temporalidades cotidianas distintas, assim como à diversidade de vivências de sofrimento e processos de adoecimento (BRITO, 2005; NEVES et al., 2011; ROTENBERG et al., 2001).

Este artigo visa tratar a relação entre saúde, subjetividade e trabalho a partir das contribuições das Clínicas do Trabalho e do enfoque de gênero, analisado sob a perspectiva da apropriação do tempo de trabalho. Para tanto, recorremos ao levantamento do estado da arte acerca do tema em foco, inclusive a análises decorrentes de investigações por nós realizadas. Inicialmente apresentaremos os pressupostos teóricos, as concepções e os conceitos vinculados a tais abordagens, valorizando o diálogo sinérgico entre elas, o que nos parece profícuo para um melhor entendimento da relação saúde e trabalho. Em seguida, discutiremos alguns resultados de investigações que focaram situações de trabalho do setor de serviços, tais como educação, saúde e telemarketing, com base na articulação dessas contribuições teóricas.

\section{Canguilhem e as Clínicas do Trabalho}

A saúde, para Canguilhem (1990b, 2001), está ligada tanto ao meio em que vivemos, quanto à capacidade que temos e desenvolvemos, individual e coletivamente, para transformá-lo segundo nossos anseios. Trata-se de uma noção associada à capacidade de produção de novas normas de vida (e não apenas mera ausência de doença) e que ressalta a existência de uma dimensão do corpo humano só acessível ao próprio sujeito, sinalizando a necessidade de constante diálogo com aquele que vivencia a experiência do seu corpo, da sua dor e do seu adoecimento para compreendê-la (CAPONI, 1997; BRITO; NEVES; ATHAYDE, 2003). Nesta concepção, viver implica um debate entre diferentes normas, um processo dinâmico e nunca previsível, que não é "apenas submissão ao meio, mas também instituição de seu próprio meio", estabelecendo "valo- 
res, não apenas no meio, mas também no próprio organismo" (CANGUILHEM, 1990b, p. 175). Há condições que são impostas, pois somos obrigados a conviver em um meio com características muitas vezes não desejadas: destruição ecológica, distribuição perversa da riqueza, condições e formas de organização do trabalho desfavoráveis ou inaceitáveis, falta de segurança, analfabetismo ou escolaridade precária, alimentação deficiente etc. A normatividade manifesta-se na capacidade de lidar e transformar essas condições, desenvolvendo caminhos para a criação de novas normas, escolhendo modos de vida alternativos às adversidades e ampliando as margens de "tolerância contra o meio" através de conquistas em diversos setores (sociais, científicos, tecnológicos etc.). Mas ser normativo não se resume à construção de um meio mais seguro ou a uma capacidade de adaptação a ele, pois, conforme salienta Caponi (1997, p. 294), "saúde é, pois, possuir uma capacidade de tolerância ou de seguridade que é mais do que adaptativa”. Em outras palavras, a saúde relaciona-se mais à expansão do viver do que à sua conservação, envolvendo o enfrentamento dos riscos que isso comporta.

Segundo Canguilhem (1990a, p.35), para melhor compreender esta concepção de saúde, é necessário considerar o "corpo dado" e o "corpo produto", ou seja, o patrimônio genético e os modos de vida de cada um, seja por escolha ou imposição. A saúde deficiente do "corpo dado" seria "uma limitação do poder de tolerância e de compensação das agressões do meio ambiente", por exemplo, por alguma má formação orgânica. Já a saúde como expressão do "corpo produto" é uma garantia vivenciada duplamente como uma "garantia contra o risco e audácia para corrê-lo”. Segundo Caponi (1997), é o sentimento de poder ultrapassar capacidades iniciais, que pode ser experimentado pela transformação de um meio social adverso.

Ramminger (2009) alerta sobre o perigo de cairmos na simples dicotomia entre normalização social e normatividade biológica, perguntando-nos se a saúde, afinal, é uma expressão da capacidade normativa de cada organismo ou um efeito das normas sociais. Nesta direção, Le Blanc (2002) ressalta que as normas sociais não podem ser pensadas como autônomas, emancipadas do sujeito, pois depende sempre de como são valoradas e interpretadas. Cada sujeito - seja "individual" ou "coletivo" - afirma-se em relação às normas que institui ou contesta. Assim, a normalização social instituída não priva a sociedade, grupo ou indivíduo de sua capacidade normativa. Esta é, a nosso ver, uma questão fundamental para a análise dos processos saúde-doença relacionados ao trabalho, torna-se uma exigência considerar não apenas as normas sociais (os determinantes sociais), mas, simultaneamente, a capacidade dos trabalhadores de instituir outras normas, os recursos de que dispõem ou criam para lidar com o que é imposto no âmbito do conflito capital-trabalho.

Cabe aqui estabelecer uma relação com a Psicodinâmica do Trabalho, visto que, para esta abordagem clínica do trabalho, se é fácil definir a doença, o mesmo não ocorre com a saúde ou o bem-estar, de mais difícil compreensão:

Trata-se, sobretudo, de uma noção limite que constitui uma espécie de horizonte, de ponto de fuga, de ideal, jamais verdadeiramente atingido, mas colocado teoricamente por uma necessidade lógica. (DEJOURS; ABOUDCHELI, 1994, p. 127)

Nessa situação, o que conta são os movimentos postos em ação para conquistá-la ou resgatá-la, sendo, dessa forma, percebida sempre como um alvo, uma meta a ser alcançada. Christophe Dejours (LANCMAN; SZNELWAR, 2004) problematiza a relação trabalho-saúde e defende que o trabalho não é apenas fonte de sofrimento e de processos de adoecimentos, atuando também como operador de saúde e prazer. Portanto, o trabalho nunca é neutro em relação à saúde, podendo tanto favorecê-la, quanto contribuir para o adoecimento.

Com base nesses pressupostos, as "boas" condições de saúde não estariam garantidas em um local de trabalho salubre e concebido como "ideal". Em primeiro lugar, porque, em uma perspectiva de conquista permanente, os nossos ideais vão se reconfigurando, demandando contínua mobilização. Em segundo lugar, porque, como chama atenção a Ergologia por intermédio de Schwartz (2000) e de Schwartz e Durive (2010), todo homem (acrescentamos: e toda mulher) busca criar/organizar seu meio de trabalho, o que implica reconhecer que há uma multiplicidade de ideais (ao nosso ver marcada em maior ou menor medida pelas relações de classe e gênero), envolvendo um debate permanente de normas e valores. Enfim, a saúde não é um estado ideal e não é algo estático; ela é, antes de tudo, algo que se defende a cada instante, um campo de negociação cotidiana e permanente para tornar a vida viável (LANCMAN; SZNELWAR, 2004).

Quanto ao trabalho, é fundamental considerar seu caráter central em nossas sociedades e sua complexidade. Conforme preconiza a Ergonomia da Atividade, os homens e as mulheres que trabalham nunca são meros executantes, mas operadores - no sentido de que fazem gestão das exigências e das variabilidades (técnicas e humanas), não se submetendo passivamente a elas (WISNER, 1994; GUÉRIN et al., 2001; DANIELLOU, 2004) -, mesmo em um contexto social comandado pela lógica capitalista onde, do ponto de vista das relações de trabalho, esse se configura como 
mercadoria. Salientamos que mesmo vendendo sua "força de trabalho", pode-se afirmar, a partir da Ergologia, que os homens e as mulheres buscam tornar a vida vivível (SCHWARTZ, 2000), tentando tornar o meio o mais próximo possível de suas expectativas, de suas normas de vida. A ideia de local de trabalho "ideal" deve ser problematizada porque as situações de trabalho não podem ser consideradas estáticas: ela é reconstruída permanentemente pela ação dos trabalhadores no desenvolvimento das atividades.

Ao mostrar que o trabalho não se resume nunca à prescrição e que os trabalhadores nunca são meros executantes (mesmo que o taylorismo tenha deixado suas marcas até hoje), a Ergonomia da Atividade se torna uma ferramenta fundamental para demonstrar as competências mobilizadas e desenvolvidas pelas mulheres e pelos homens e todas as exigências presentes no desenvolvimento da atividade, não visando especificamente à redução dos riscos nem mesmo a erradicação da doença, mas a promoção da saúde e o desenvolvimento do poder de agir (HUBAULT, 2009). Isto é especialmente importante no caso das mulheres, na medida em que suas competências tendem a ficar ocultadas pela ideia tão difundida de que trabalho feminino requer apenas o uso de qualidades consideradas historicamente como inatas e pela negação da tecnicidade presente em suas funções (HIRATA; KERGOAT, 2003).

Para a Ergologia, a atividade remete também aos valores que estão imersos em uma situação particular. Valores que estão vinculados às normas que antecedem à atividade - impostas pelas instâncias administrativas e referentes ao contexto histórico - e valores que são ligados aos diferentes atores e às regras instituídas pelos coletivos. Na medida em que toda atividade de trabalho envolve debates de normas, Schwartz (2002) propõe uma análise que contemple a dialética do geral e do singular, que articule permanentemente o micro e o macro. É necessário considerar as normas antecedentes e as renormatizações engendradas pelos trabalhadores, pois esses sempre fazem uso de si, ou seja, sempre fazem escolhas que se remetem a valores, mesmo que pequenas (SCHWARTZ; DURRIVE, 2010). A maioria das escolhas feitas pelos trabalhadores não são percebidas facilmente, mas há algumas que podem até parecer irracionais: por exemplo, eles podem desenvolver suas atividades de um modo que julgamos ser mais difícil ou mais inseguro. Nesse sentido, protocolos de segurança elaborados sem a participação dos trabalhadores podem não ser seguidos por eles, que no desenvolvimento das atividades criam suas próprias normas ou modos de lidar com os riscos e as adversidades.

O protagonismo dos trabalhadores também é destacado pela Clínica da Atividade. De acordo com Clot (2006), a atividade de trabalho é compreendi- da como sendo triplamente dirigida: em direção a si próprio, ao objetivo de trabalho e aos outros, o que aponta, na verdade, para uma coatividade. Nesta direção, os estudos que se utilizam desta abordagem enfatizam não apenas a função psicológica do trabalho, mas como, para além desse papel, o trabalho impulsiona o desenvolvimento dos indivíduos adultos por intermédio do diálogo e pela construção dos coletivos de ofício. Ou seja, o trabalho é uma arena na qual o conflito está sendo sempre trabalhado e recebe soluções transitórias, sendo vital para o desenvolvimento da atividade. É nessa perspectiva que os métodos propostos pela Clínica da Atividade visam ampliar o poder de agir dos trabalhadores, o que implica em analisar os modos singulares que são adotados no desenvolvimento da atividade.

Já a Psicodinâmica do Trabalho define o trabalho como atividade coordenada de homens e mulheres para responder ao que não está posto pela organização prescrita do trabalho (LANCMAN; SZNELWAR, 2004). Segundo esta vertente, os trabalhadores recorrem a um tipo específico de inteligência prática, astuciosa, enraizada no corpo, que é alertada quando um acontecimento irrompe nas situações cotidianas de trabalho. Ou seja, ela é fundamentalmente subversiva e criativa em relação à prescrição e sua subutilização é patogênica (DEJOURS, 1993). Diante das variabilidades encontradas em toda atividade, os sujeitos constroem, então, novas formas de realização do trabalho e inventam diferentes maneiras de articular-se a ele, subvertendo o patrimônio cultural do coletivo de trabalhadores.

Algumas condições psicossociais mobilizam o aparecimento da inteligência astuciosa, tais como a ressonância simbólica e o espaço público (DEJOURS; ABDOUCHELLI, 1994). A ressonância simbólica diz respeito ao encontro entre o teatro da situação atual do trabalho e o teatro interno, herdado das experiências de vida. É a articulação da história singular do sujeito ao mundo atual e público do trabalho. E o espaço público interno de discussões sobre o trabalho é construído pelos próprios trabalhadores ao estabelecerem e compartilharem relações (laços) de confiança e de cooperação - que, por sua vez, dependem não apenas dos requisitos psicoafetivos (desejo/ vontade de cooperação), mas principalmente do estabelecimento de valores e regras (éticas) comuns. Precisa, ainda, que a inteligência astuciosa mobilizada diante de insuficiências e contradições da organização prescrita seja reconhecida (contribuição da concepção), necessitando, para isso, que se torne visível e transparente (DEJOURS, 1993).

Para que o processo de mobilização subjetiva ocorra, faz-se necessário, portanto, que a inteligência astuciosa seja reconhecida. Reconhecimento que se dá mediante a retribuição do julgamen- 
to proferido pela hierarquia, eventualmente pelos clientes, acerca da utilidade da contribuição do operador na organização do trabalho e a retribuição do julgamento de beleza e de originalidade elaborado pelos próprios pares quanto à qualidade e ousadia de seu feito, além dos regulamentos formalmente estabelecidos (DEJOURS, 1993).

Se o reconhecimento social desse fazer é também capitalizado pelo sujeito no registro do ser, da identidade (sempre inacabada), é, contudo, o reconhecimento de seus pares que confere ao sujeito que é julgado o sentimento de pertencimento a um coletivo de trabalho. Assim, a dinâmica do reconhecimento, que possibilita a construção por parte dos sujeitos do sentido no/do trabalho, mostra-se como um desenvolvimento teórico importante para se compreender o que favorece a mobilização no trabalho de homens e mulheres (considerando aqui suas especificidades) e, consequentemente, as possibilidades de transformação do sofrimento - devido às exigências, às pressões e aos constrangimentos do trabalho - em prazer (LANCMAN; SZNELWAR, 2004).

Segundo Lancman e Sznelwar (2004), os trabalhadores elaboram defesas para lutar contra o sofrimento. Parte-se, assim, da compreensão de que os trabalhadores não estão passivos em relação à organização do trabalho, mas são capazes de se proteger elaborando defesas que escondem ou evitam o sofrimento que os acomete. Para esse autor, mesmo considerando seu caráter complexo e problemático, uma das descobertas empíricas mais surpreendentes dos estudos desenvolvidos foi exatamente a existência da construção coletiva de estratégias defensivas, específica de cada grupo social e relacionada à natureza de cada organização do trabalho. Isso é possível porque, de acordo com Lancman e Sznelwar (2004), "as estratégias defensivas funcionam como regras. Como toda regra elas supõem um consenso ou um acordo partilhado" (DEJOURS; ABDOUCHELI, 1994, p. 128), diferenciando-se, dessa forma, dos mecanismos de defesa que são individuais. Ou seja, como sinaliza o próprio autor, as estratégias defensivas podem atuar como "regras" defensivas. Ademais, a construção e o funcionamento dessas estratégias contribuem para a própria estruturação dos coletivos de trabalho (LANCMAN; SZNELWAR, 2004, p. 76).

Cabe considerar que as estratégias coletivas de defesa contra o sofrimento no trabalho diferem entre mulheres e homens, considerando os trabalhos tipicamente femininos e masculinos, particularmente no que diz respeito à morte e ao sofrimento do corpo de outro (MOLINIER, 1995). Entre as enfermeiras, as estratégias de defesa consistem em "envolver" a vulnerabilidade dos corpos com uma "cerca" protetora (GERNET, 2009), visando serem menos afetadas. Desta forma, conseguem lidar (ao menos parcial- mente) com a angústia gerada pela vulnerabilidade do outro. Isto significa que produzem um distanciamento subjetivo do real do trabalho de cuidado, que pode vir acompanhado de brincadeiras e risos sobre a própria experiência. Já entre os homens, em funções tipicamente masculinas como de operários da construção civil, tais estratégias tendem a se fundar na negação do real, sendo expressas através de comportamentos de enfrentamento do risco.

Em suma, as perspectivas teóricas aqui apresentadas apontam a necessidade de compreender os modos como a saúde é implicada no trabalho, seja positivamente como fonte de desenvolvimento psíquico e de acesso a modos de vida, seja negativamente, impedindo-o, o que se reflete em sofrimento, adoecimentos e acidentes. Contribuem para a incorporação da questão da subjetividade nas análises da relação saúde-trabalho - subjetividade que se constrói na relação com o meio, no desenvolvimento da atividade e que é evidenciada nas lutas cotidianas pela afirmação de si, contra os sofrimentos e nas invenções de modos singulares de realização do trabalho. Julgamos, entretanto, que, para avançarmos nessa compreensão, faz-se imprescindível a incorporação da ótica das relações sociais de gênero nos estudos acerca dos mundos do trabalho e da saúde do trabalhador, o que nos propomos a discutir a seguir.

\section{Trabalho e relações de gênero com ênfa- se na apropriação do tempo de trabalho}

As Clínicas do Trabalho alertam que as situações de trabalho não se repetem de forma idêntica ao longo do tempo, variando inclusive devido aos modos singulares de trabalhar. Nesse sentido, evidenciam os processos de subjetivação vivenciados no trabalho, questão também contemplada pelos estudos de gênero. A incorporação desta perspectiva pela Psicodinâmica do Trabalho, conforme sinalizamos anteriormente, indica claramente a pertinência em articular o "olhar" clínico ao enfoque das relações de gênero. Portanto, recusamos o entendimento do trabalho enquanto prática assexuada devido à variabilidade da organização técnica e social com base no sexo.

Um conceito central a ser considerado neste contexto é o de divisão sexual do trabalho, que se refere à designação prioritária dos homens à esfera produtiva e das mulheres à esfera reprodutiva (HIRATA; KERGOAT, 2007). Trata-se de uma forma de divisão do trabalho construída histórica e socialmente a partir da atribuição de valor à esfera da produção. A divisão sexual do trabalho é calcada em dois princípios organizadores: o princípio da separação, expresso pela noção de que há trabalhos 
de homens e trabalhos de mulheres, e o princípio hierárquico, que embasa o maior valor atribuído ao trabalho masculino - fruto da qualificação - em oposição ao trabalho feminino, associado a qualidades do gênero feminino. Análises antropológicas em diversos grupos sociais atestam a permanência destes princípios, embora suas modalidades (lugar das mulheres no mercado produtivo, concepção de trabalho reprodutivo) variem fortemente no tempo e no espaço (KERGOAT, 2009). É com base nesta constatação que Hirata e Kergoat (2007) se referem a um paradoxo na divisão sexual do trabalho: "nessa matéria, tudo muda, mas nada muda" (HIRATA; KERGOAT, 2007, p. 597).

A análise histórica de alguns ofícios revela que, entre as possibilidades no século XIX para o confinamento doméstico de determinados segmentos de classe do sexo feminino, encontravam-se, comumente, as profissões de magistério, enfermagem e outras ligadas ao domicílio. Ou seja, a inserção dessas mulheres no mercado de trabalho se dava em profissões que tinham (ou que passaram a ter) características similares às da esfera doméstica. Evidencia-se, assim, a condição sexuada do mercado de trabalho, no qual as características consideradas próprias da "natureza feminina" são desqualificadas simbólica e economicamente a partir da concepção de que expressam apenas "qualidades" femininas (KERGOAT, 1986). Neste sentido, o conceito de divisão sexual do trabalho se refere não só à distribuição desigual no mercado de trabalho, mas remete a desigualdades sistemáticas entre os gêneros, traduzindo-se em uma "diferenciação para hierarquizar as atividades e, portanto, os sexos, em suma, para criar um sistema de gênero" (HIRATA; KERGOAT, 2007 , p. 596). Assim, a qualificação que é demandada às mulheres - expressa nas qualidades de destreza, minúcia, paciência, cuidados com o outro etc. -, por não ser adquirida em canais formais e ser considerada própria da "natureza feminina", não é reconhecida e valorizada. Desconsidera-se, assim, que tal qualificação reúne características que, na verdade, decorrem de uma aquisição coletiva (feminina) possibilitada desde a infância pelas atividades realizadas no âmbito doméstico (HIRATA; KERGOAT, 1988; BRITO, 1999; NEVES; SELIGMANN-SILVA, 2001; MARCONDES et al., 2003).

A inserção no magistério ou na enfermagem, portanto, mais do que uma opção profissional, significa uma oportunidade que as mulheres encontram para exercitar habilidades e atitudes aprendidas em seu processo de socialização, na medida em que essas ocupações demandam qualidades tidas como inatas a elas, tais como atenção, dedicação, carinho e paciência (SOARES, 2005).
No que se refere ao trabalho de telemarketing, especificamente de recepção de chamadas, ao atender o cliente, concretiza-se a dimensão singular da prestação do serviço. Neste caso, as mulheres são consideradas mais “apropriadas”, e não mais qualificadas, para este tipo de tarefa, como aponta Segnini (2001), em decorrência de atributos pessoais, construídos a partir de estereótipos sexistas, como: "voz mais suave", "convincente".

A este repeito, Messing e Östlin (2006) criticam a ideia de divisão sexual do trabalho como fruto de leis "naturais" (grifo original das autoras), como se as mulheres atuassem em trabalhos mais apropriados para seu corpo e papel social. As autoras ponderam que, se assim fosse, "a divisão do trabalho seria boa para a saúde das mulheres" (MESSING; ÖSTLIN, 2006, p. 4). Análises ergonômicas do trabalho no caso, por exemplo, de professores(as), revelam o quanto as habilidades técnicas e posturais dominadas pelos(as) professores(as) no exercício de seu ofício repercutem sobre sua saúde (MESSING; SEIFERT; ESCALONA, 1997).

As assimetrias entre homens e mulheres também se expressam no âmbito doméstico, dada a responsabilidade da mulher pela casa, independentemente do seu papel no mercado produtivo. Expressam-se nos usos diferenciados do tempo para homens e mulheres na esfera pública e privada, de forma que a análise destes tempos permite "conhecer a dinâmica das relações de poder existentes entre os sexos" (BANDEIRA, 2010, p. 49).

Para apreender a interação entre as esferas profissional e doméstica a partir da concepção do tempo como construção social, buscamos a contribuição de Elias (1998). Segundo este autor, o tempo é um símbolo social oriundo de um longo processo de aprendizagem através de diversas gerações. Os processos de urbanização e a expansão do comércio levaram à maior:

[...] necessidade de sincronizar o número crescente das atividades humanas, e de dispor de uma rede de referências temporais cuja extensão regular pudesse servir de quadro de referência. (ELIAS, 1998, p. 46)

Trata-se de coordenar e sincronizar o desenrolar das atividades humanas, tanto entre si, quanto com os processos físicos externos ao homem, o que é tão mais perceptível quanto mais as sociedades são vastas, populosas, diferenciadas e complexas.

A análise empreendida por Elias (2008) revela uma visão de sociedade como uma rede de interdependência mútua entre os indivíduos que formaria as chamadas configurações, de forma análoga a um jogo de xadrez, uma conversa ou uma dança em que qualquer ação realizada com uma relativa independência atua sobre o(s) outro(s) elemento(s) da relação, seja ele o 
parceiro na dança, o interlocutor na conversa ou o oponente no jogo (ELIAS, 1994a; 1994b; 2008). Os conceitos de interdependência e de configuração nos parecem essenciais para analisar as relações trabalho-saúde do ponto de vista dos usos do tempo na gestão da vida cotidiana. Tabboni (2001), por exemplo, utiliza a noção de configuração para analisar as relações atuais entre o tempo de trabalho e o de lazer, ressaltando o quanto a modificação em um deles necessariamente afeta o outro. No contexto brasileiro, Dedecca, Ribeiro e Ishii (2009) aplicam este conceito à apropriação do tempo diário, mostrando como "aumentos da jornada no mercado de trabalho devem ser compensados com reduções da jornada destinada à família ou ao lazer" (DEDECCA; RIBEIRO; ISHII, 2009, p. 72).

Nesta direção, Curie et al. (1990) criticam a dicotomia vida no trabalho $\mathrm{x}$ vida fora do trabalho através da noção de "sistema de atividade", que se refere aos processos interdependentes entre as atividades em vários domínios da vida. Esta abordagem é similar à defendida por Aguiar (1997) no sentido da necessidade de romper a oposição entre o espaço doméstico e o espaço público. Trata-se de analisar as temporalidades segundo a articulação entre os trabalhos doméstico e assalariado, o que implica adotar uma perspectiva relacional que considere as diferentes inserções sociais em ambos os espaços (CYRINO, 2009).

No Brasil, apesar do aumento da inserção feminina no trabalho remunerado, as mulheres têm, além da diferença salarial, uma jornada total (remunerada somada à doméstica) superior à dos homens. Para elas, o ingresso no mercado de trabalho não representa uma redução da jornada em afazeres domésticos, situação que contrasta com a dos homens, em que mesmo o desemprego não significa maior tempo dispendido em afazeres domésticos (DEDECCA, 2004). Neste contexto, concordamos com Dedecca, Ribeiro e Ishii (2009) quando advogam que as políticas de trabalho não devam se restringir ao mercado, sendo necessário considerar o núcleo familiar, que é justamente o mais refratário a transformações na direção da igualdade de gênero (PINHEIRO et al., 2008).

Se as assimetrias entre os sexos podem parecer óbvias por compor nossa vida cotidiana, quando transformadas em objeto de estudo elas dão visibilidade ao caráter social desta construção, alimentando a discussão sobre a igualdade de gênero nas esferas pública e privada através da riqueza proveniente do campo empírico.

As análises a seguir baseiam-se em investigações que trataram da saúde de trabalhadoras ${ }^{5}$ da educação, de saúde e telemarketing a partir dos enfoques que apresentamos ao longo deste artigo.

\section{Situações empíricas da relação saúde e trabalho a partir desses enfoques}

Atentas às afinidades e especificidades teóricas encontradas nas abordagens e perspectivas clínicas, para fundamentação das análises sobre os resultados das pesquisas tratadas neste tópico, que foram por nós desenvolvidas, recorreremos apenas às que se mostram mais pertinentes. Entendemos que os exemplos aqui citados contribuirão para demonstrar o interesse em articular o olhar presente em tais teorias com o enfoque sociológico das relações de gênero.

\section{Trabalhadoras da educação}

Em nossos estudos, observamos que, por exemplo, a "feminização" do magistério do Ensino Fundamental, proporcionada pela expansão do ensino de massa, entre outros fatores, não se limitou apenas à questão da presença feminina maciça nessa atividade. Ela também evidenciou o fato de, ao ocuparem-na, terminarem por conformar outro campo profissional, sedimentando, assim, um tipo específico de saber-fazer considerado como próprio da condição feminina, uma vez que, socialmente, as mulheres são consideradas as guardiãs da afetividade e do futuro das novas gerações. Ou seja, a produção de uma prática em que a afetividade é associada aos atributos maternos e não uma característica provavelmente condizente à atividade docente (NEVES; SELIGMANN-SILVA, 2001).

Ao longo desses estudos sobre o trabalho docente, pudemos levantar um conjunto de queixas acerca dele. Identificamos o custo psíquico que tem para a saúde das professoras do ensino fundamental de escolas públicas, dentre outros: a formação profissional deficiente; as precárias condições de trabalho; a extensiva jornada de trabalho (dupla/tripla jornada); a existência de classes numerosas; a inexistência de tempo para descanso e lazer; o envolvimento emocional com os problemas dos alunos; o sentimento de culpa por não darem conta satisfatoriamente das atividades domésticas e familiares; e, fundamentalmente, a desvalorização social de seu trabalho - o não reconhecimento simbólico e econômico (BRITO; NEVES; ATHAYDE, 2003; BRITO; ATHAYDE, 2003; NEVES; SELIGMANN-SILVA, 2006; GOMES; BRITO, 2006).

A contaminação do tempo livre pelo trabalho - tanto o da escola, quanto o doméstico -, principalmente durante o fim de semana, está fortemente marcada pela questão de classe e de gênero na me-

\footnotetext{
${ }^{5}$ Esclarecemos que, independentemente da regra gramatical (que se constitui ela mesma em uma produção social), estaremos nos referindo aos trabalhadores e às trabalhadoras destes setores sempre no feminino - as trabalhadoras - devido ao fato de sua composição ser majoritariamente de mulheres.
} 
dida em que, além de tarefas pendentes do trabalho escolar, as professoras ainda devem arcar sozinhas com as demandas cotidianas do trabalho doméstico. Isto levando-se em conta as restrições orçamentárias vinculadas aos segmentos da sociedade a que pertencem em sua maioria. De certa forma, este dado explica o cansaço expresso, já e sobretudo, no primeiro dia de trabalho da semana na escola. De acordo com os relatos dos professores do sexo masculino, o dia mais cansativo da semana é a sexta-feira. Logo, supomos que parte dos professores (pelo menos nos fim de semana) não leve tarefas escolares para casa e que, como também não realizam tarefas domésticas (a não ser em raras exceções), a segunda-feira é o dia da semana em que se sentem menos cansados (NEVES; SELIGMANN-SILVA, 2006).

Como reação a tal situação de trabalho, as professoras desenvolvem defesas (LANCMAN; SZNELWAR, 2004), tais como o "faltar para não faltar ao trabalho" (para não adoecer), as saídas constantes de sala de aula, o individualismo e o desengajamento afetivo e cognitivo (NEVES; SELIGMANN-SILVA, 2006).

No enfrentamento cotidiano da realidade escolar, vimos, entretanto, que essas não desenvolvem apenas movimentos reativos frente ao sofrimento e contra a doença (DEJOURS, 1993), mas que há também a ressingularização e a renormatização do trabalho (SCHWARTZ, 2000). Encontramos professoras que exercitam diariamente novas formas de lidar com os limites e as dificuldades da docência ao elaborarem modos de regulação das variabilidades inerentes à sua atividade, fazendo com que escolas, sem recursos de toda ordem, mantenham-se, sobretudo, em função da criatividade de suas docentes. Ou seja, exercitam ações propositivas de luta permanente pela afirmação de si, de sua potência de vida, pela realização de seu trabalho e de prazer e pela busca de sua saúde (BRITO; ATHAYDE, 2003; NEVES; SELIGMANN-SILVA, 2006).

Quanto à dimensão do prazer no trabalho, ele é facilmente evocado pelas docentes, sobretudo na relação afetiva que estabelecem com os alunos e no fato de conceberem e perceberem os resultados de seu trabalho na formação deles. Remetem-se, assim, principalmente, à dimensão afetiva existente na relação educativa, o que não deixa de configurar atitude paradoxal, em que amor e saturação emocional em relação aos alunos se impõem simultaneamente e sob conflito.

\section{Trabalhadoras da saúde}

Observamos também uma intensa mobilização subjetiva/afetiva entre auxiliares de enfermagem que atuam em Unidades de Terapias Intensivas Neonatais (UTINs) quando afirmam: "desde o momento que a gente tá aqui, tá na chuva pra se molhar, né, não dá pra gente deixar de atender" (MASSON; BRITO; ATHAYDE, 2011, p. 894). Afirmações deste tipo conjugadas a observações realizadas na UTI nos permitiram detectar uma regra de ofício (CRU, 1988) implícita presente nesse coletivo de trabalho: não se pode deixar de atender os bebês, mesmo que a superlotação represente sobrecarga de trabalho e maior dificuldade para lhes dar assistência.

Além disso, a escassez ou a má qualidade dos materiais e instrumentos levam a atividades contrariadas ou mesmo impedidas (CLOT, 2006), conduzindo muitas vezes a sentimento de impotência, fadiga crônica, descompensações e ressentimento. Essas duas situações de trabalho são produtoras de sofrimento entre as auxiliares: não poder receber todos os bebês que procuram o hospital e realizar as atividades de cuidado sem dispor de materiais de qualidade.

Outro sinal da intensa mobilização no trabalho é a gestão do tempo realizada pela equipe de enfermagem (SOUZA, 2010). Para realizarem suas tarefas dentro do tempo previsto, acabam trabalhando em um ritmo acelerado, encurtam ou deixam de realizar refeições/lanches, praticamente não realizam pausas (algumas delas chegam a considerar como pausas os momentos que param de realizar procedimentos para fazer relatos no prontuário), ficam horas consecutivas de pé, evitam inclusive as idas ao banheiro ou para beber água. A pesquisa de Masson (2007) apontou que mesmo o horário de almoço (quando usado) não representa um afastamento completo da atividade, pois elas dizem que continuam com a "cabeça aqui em cima [na UTI]” (p.154). Observa-se, então, um forte uso de si (SCHWARTZ, 2002), completamente contrário a uma ideia de que o trabalho das auxiliares seria "repetitivo" e de pura "execução". Podemos concluir ainda que esta atividade implica também grande sobrecarga cognitiva e afetiva, pois até mesmo uma auxiliar assim se expressa: "esse é um trabalho com uma grande sobrecarga emocional”.

As auxiliares argumentam que a profissão de enfermagem é mal remunerada e que precisam trabalhar muito para conseguirem uma renda melhor (vários empregos ou plantões extra), o que acarreta diversos problemas de ordem física, mental e social. No caso de trabalho noturno (ou melhor, realizado durante a madrugada), uma auxiliar afirma que, no dia seguinte, fica "passando mal de sono, enjoos, sonolência, irritação", precisando de mais de um dia para recuperar-se da noite não dormida (SOUZA, 2010).

Podemos perceber que elas não se sentem reconhecidas (DEJOURS, 1993) pelo importante papel que exercem na recuperação dos bebês. As auxiliares falam que não há uma "valorização profissional" do trabalho delas pela hierarquia. Chamam a atenção 
para a falta de elogios também por parte dos familiares, apontando a ausência de reconhecimento da importância do seu trabalho também por parte deles, que atribuem todo o sucesso dos tratamentos à ação dos médicos. Entretanto, detectamos um valor construído coletivamente por este grupo - "fazer o melhor" e "dar o melhor de si" -, indicando que o prazer e o sentido do trabalho são conquistados especialmente pelo reconhecimento dos pares (MASSON, 2007). Há casos em que as mães retornam ao hospital meses após a alta para agradecer pelos cuidados realizados na UTIN, com a criança saudável no colo, o que para elas é uma demonstração de reconhecimento, só que posterior ao momento do tratamento (SOUZA, 2010).

Como os hospitais funcionam de forma ininterrupta, as equipes de enfermagem precisam atuar em plantões noturnos e nos fins de semana. Vale lembrar que os hospitais brasileiros adotam plantões longos - geralmente de 12 horas. Neste sentido, os trabalhadores e trabalhadoras vivenciam "desafios temporais" que decorrem do desencontro de horários em relação à família e à sociedade como um todo (FISCHER; MORENO; ROTENBERG, 2004). Tais situações implicam estratégias de gerenciamento do tempo e de organização da vida cotidiana vividas de forma complexa pelas mulheres em função da relevância do trabalho doméstico para estas (ROTENBERG et al., 2012).

Um aspecto desta questão é observado no estudo desenvolvido por Ferreira (2009), com base em oficinas de discussão que reuniam pesquisadores e trabalhadores da enfermagem inspiradas no dispositivo dinâmico de três polos (SCHWARTZ, 2000). Ao focar as relações entre o trabalho e a saúde, as trabalhadoras revelam o caráter obrigatório do cuidado dos filhos e da casa, mesmo após o plantão noturno, enquanto entre os homens que voltam do mesmo plantão a prioridade é dormir.

Outro estudo com enfermeiras de plantões noturnos enfatiza valores associados às relações de gênero no âmbito familiar (RIBEIRO-SILVA, 2006), em que o emprego do tempo em atividades domésticas é visto como outra forma de trabalhar. Neste contexto, as atividades realizadas no âmbito doméstico são consideradas trabalho, o que condiz com o enfoque que temos dado a esta categoria analítica. Trata-se, assim, de uma enorme massa de trabalho efetuada gratuitamente pelas mulheres, "que é realizado não para elas mesmas, mas para outros, e sempre em nome da natureza, do amor e do dever materno" (HIRATA; KERGOAT, 2008, p. 597).

A análise dos usos do tempo em trabalhadoras da enfermagem confirma a priorização do cuidado de outros e de tarefas domésticas em detrimento de atividades voltadas para si próprias, como o lazer e o cuidado de si (RIBEIRO-SILVA; ROTENBERG, 2008). Estas observações remetem ao constructo do "tempo feminino" como o tempo para os outros (JURCZYK, 1998). A relevância do âmbito doméstico na distribuição do tempo das mulheres, que necessariamente se articula ao menor tempo para si, constitui uma modalidade de interdependência das formas de apropriação do tempo como propõem Dedecca, Ribeiro e Ishii (2009). Em outras palavras, como o dia dura, invariavelmente, 24 horas, o caráter "obrigatório" atribuído pelas trabalhadoras à realização (ou ao gerenciamento) do trabalho doméstico tem implicações em outros tempos da vida. Neste contexto, menor tempo para si tende a resultar em menores possibilidades de negociação cotidiana pela saúde, levando a diferenciações atravessadas pelas questões de gênero.

De fato, estudos quantitativos atestam as relações entre realizar o trabalho doméstico e a recuperação das profissionais da enfermagem em relação ao trabalho profissional. A análise da recuperação das trabalhadoras mostra que o repouso no hospital durante os plantões noturnos se associava à maior recuperação das trabalhadoras apenas entre as que tinham jornada doméstica curta, ou seja, de até 10 horas por semana (SILVA-COSTA et al., 2011). Em outras palavras, a alta carga de trabalho doméstico parece neutralizar os aspectos benéficos do repouso à noite na recuperação das trabalhadoras, revelando as complexas relações entre as esferas profissional e doméstica.

A questão do trabalho doméstico e seu papel como estruturador de um contingente expressivo de mulheres explica a escolha pelos plantões noturnos de enfermeiras e auxiliares de enfermagem que referem repercussões do trabalho noturno no sono, ao mesmo tempo em que referem preferir este horário por possibilitar conciliar o trabalho profissional com a realização do trabalho doméstico durante o dia (SOARES, 2005).

\section{Trabalhadoras do telemarkting}

A tentativa de conciliar trabalho profissional e doméstico é observada também na atividade de telemarketing. A jornada de seis horas diárias é um dos atrativos para as mulheres, que buscam conjugar tarefas domésticas, cuidado com filhos e trabalho remunerado (ROCHA et al., 2006; NOGUEIRA, 2006). No entanto, essa conciliação não se realiza isenta de consequências devido à intensidade dessa atividade.

Os estudos ergonômicos revelam que as relações de gênero interferem no processo e na organização do trabalho (MESSING, 1998; TEIGER, 1993). Nas atividades de telemarketing, as mulheres sofrem mais a intensificação da repetitividade das tarefas justamente porque são capazes de atender mais clientes e dar 
entrada em maior número de dados simultaneamente durante uma mesma jornada de trabalho. Por sua vez, aumentam o uso de suas estruturas ósteomusculares, elevando os riscos de aquisição das Lesões por Esforços Repetitivos - LER (PACHECO, 2002).

A gestão do tempo é o âmago da atividade do telemarketing, devendo as trabalhadoras realizar suas tarefas em um tempo médio de atendimento (TMA) sob pressão da supervisão. Tempo que na maioria das vezes não é suficiente para dar conta de todas as prescrições. É nesta dinâmica que se realizam as competências, na capacidade das teleoperadoras de além de controlarem o TMA e atenderem os clientes, registrarem adequadamente o seu atendimento. E as competências ditas femininas são as mais requisitadas para esta tarefa, por serem as mulheres consideradas mais apropriadas por seus atributos, como uma voz suave, que seria "mais confiável” para a realização das operações à distância.

Estudos sobre as relações de gênero verificam ainda que, quando o trabalho se qualifica, são priorizados os trabalhadores do sexo masculino (HIRATA, 2002). Identificamos isto no telemarketing quando observamos uma variação entre a distribuição de homens e mulheres no interior das empresas. As mulheres são mais frequentemente destinadas ao Serviço de Atendimento ao Cliente (SAC), em que o trabalho exige menor qualificação e são requeridas mais habilidades de relacionamento com o cliente, pois é onde "pipocam" os maiores problemas. E os homens se concentram nos setores de apoio técnico e nas áreas atendidas pelo telemarketing bancário, que privilegia estudantes universitários masculinos, com salários mais elevados e onde o trabalho é realizado em melhores condições (OLIVEIRA, 2011).

Assim, a relação com a tecnologia é sexuada e a relação de trabalho implica uma relação entre os sexos (HIRATA; KERGOAT, 2008). As características sexuais vão construir trajetórias ocupacionais e diferenças em relação às possibilidades de se alocarem e realocarem na estrutura ocupacional (SORJ, 2000). A feminização do trabalho em telemarketing, com procedimentos altamente padronizados e controlados, no intuito de aumentar sua eficiência e diminuir custos, é uma das expressões de sua racionalização (SEGNINI, 2001; HIRATA, 2002).

A amputação da atividade possível remete tanto ao que os trabalhadores "não podem fazer, quanto ao que eles fazem, e aquilo que se teria querido ou podido fazer, aquilo que se pensa ou se sonha fazer" como afirma Clot (2006, p. 116). A função psicológica no trabalho para Clot é o que se faz no universo dos outros para dele participar ou se afastar. Essa função se perde quando se confunde com execução de procedimentos, quando a atividade é contrariada, privando as trabalhadoras de endereçarem e destinarem sua atividade subjetiva.

Em suma, as dificuldades das trabalhadoras em lidar com as prescrições contraditórias, associadas ao rígido controle e à pressão intensa para realização do trabalho, favorecem o aparecimento de diversas situações de adoecimento. Isto pode levar a um distanciamento das teleoperadoras em relação à qualidade do seu atendimento e do serviço prestado, rompendo dessa forma com a produção de sentido desse trabalho. Quando não reconhecidas em sua iniciativa, isto se torna um fator agravante para o sofrimento. O trabalho, em seu duplo estatuto, visa a uma produção de serviços (ou de objetos) e a uma procura de si. Para que isto se realize, é necessário que a dinâmica do reconhecimento aconteça.

Desta forma, o sentido do trabalho é fruto do seu reconhecimento social, que detém forte componente simbólico. Essa construção de sentido é intensamente atravessada pela possibilidade de a situação atual de trabalho fazer eco (ressonância simbólica) na história pessoal e nas expectativas atuais de cada um.

\section{Considerações finais}

A noção de saúde de Canguilhem permite afirmar que as possibilidades de caminhar em direção à saúde não são as mesmas para os diferentes grupos humanos, devendo-se considerar as implicações das relações sociais de classe e gênero para essas negociações cotidianas que visam a afirmar a vida. Assim, a análise dos perfis de morbidade e mortalidade deve, a nosso ver, ser conjugada com outras que apontam os meios de que os sujeitos e grupos dispõem para avançar no sentido de busca do ideal de saúde que construíram. Dito de outra maneira, a análise das patologias que acometem os trabalhadores e trabalhadoras deve dar-se neste quadro de referência, que é a saúde como capacidade de criação de novas normas de vida.

Neste contexto, a noção do tempo como elemento organizador da vida em sociedade se revela útil na análise das imbricações entre o trabalho remunerado e o doméstico. Ao gerar constrangimentos do tempo diferentes para homens e mulheres, a divisão sexual do trabalho pode ter implicações diferenciadas na saúde de homens e mulheres em termos de maior ou menor margem de tolerância ao meio. Mais do que revelar um acúmulo de trabalhos entre as mulheres, o estudo das relações entre gênero, trabalho e usos do tempo alimenta discussões sobre políticas sociais voltadas para a reprodução social, associando-se às ati- 
vidades de organização domiciliar, de lazer e de sono. De fato, como comentam Rotenberg et al. (2010), o Brasil tem avançado em direção ao reconhecimento do valor do trabalho reprodutivo, haja vista a incorporação do trabalho doméstico na Pesquisa Nacional por Amostra de Domicílio, do Instituto Brasileiro de Geografia e Estatística (IBGE). Busca-se, assim, implementar pesquisas sobre os usos do tempo no sentido de subsidiar políticas públicas voltadas à maior equidade na divisão sexual do trabalho.

Em relação à articulação entre as vertentes de análise apresentadas no artigo, pensamos que compreender a atividade de trabalho de homens e mulheres pode ser estratégico para se captar como a divisão sexual do trabalho se efetiva nos cotidianos singulares, podendo contribuir para evidenciar seja sua persistência, seja sua ruptura ou superação parcial. Por fim, parece-nos importante salientar que este conjunto de contribuições mostra que o movimento, a dinâmica e a mudança permanente inerentes à vida (inclusive a de trabalho) são aspectos que precisam ser contemplados nas análises sobre a relação entre o trabalho e a saúde.

As análises da subjetividade no trabalho revelam a importância do reconhecimento social do trabalho, cuja natureza tem forte componente simbólico, e possibilita a construção do sentido no trabalho por parte dos sujeitos. Do reconhecimento depende, na verdade, o sentido do sofrimento. Logo, a forma possível de subverter esse sofrimento será dar sentido e reconhecimento ao trabalho realizado.

\section{Contribuições de autoria}

Todas as autoras trabalharam na concepção do artigo, na elaboração do texto e em sua revisão final.

\section{Referências}

AGUIAR, N. Gênero e Ciências Humanas: desafio às ciências desde a perspectiva das mulheres. Rio de Janeiro: Rosa dos Tempos, 1997.

AROUCA, A. T. Contribuição à análise epidemiológica dos acidentes de trânsito. 1975. $221 \mathrm{f}$. Tese (Doutorado em Ciências Médicas)-Universidade Estadual de Campinas, Campinas, 1975.

BANDEIRA, L. Importância e motivações do Estado Brasileiro para pesquisas de uso do tempo no campo de gênero. Revista Econômica, Niterói, v. 12, n. 1, p. 47-63, 2010.

BRITO, J. Saúde, trabalho e modos sexuados de viver. Rio de Janeiro: Fiocruz, 1999.

. Saúde do trabalhador: reflexões a partir da abordagem ergológica. In: FIGUEIREDO, M. et al. (Org.). Labirintos do trabalho: interrogações e olhares sobre o trabalho vivo. Rio de Janeiro: DP\&A, 2004. p. 302-321.

. Trabalho e saúde coletiva: o ponto de vista da atividade e das relações de gênero. Ciência e Saúde Coletiva, Rio de Janeiro, v. 10, n. 4, p. 879-890, 2005.

BRITO, J.; ATHAYDE, M. Trabalho, educação e saúde: o ponto de vista enigmático da atividade. Trabalho, Educação e Saúde, Rio de Janeiro, v. 1, n. 2, p. 63-89, 2003.

BRITO, J.; NEVES, M. Y.; ATHAYDE, M. (Org.). Cadernos de textos. Programa de formação em saúde, gênero e trabalho nas escolas. João Pessoa: Editora Universitária/UFPB, 2003.
CAPONI, S. Georges Canguilhem y el estatuto epistemológico del concepto de salud. Santa Catarina. História, Ciência, Saúde-Manguinhos, Rio de Janeiro, v. 4, n. 2. p. 287-307, 1997.

CANGUILHEM, G. La santé: concept vulgaire e question philosophique. Paris: Sables, 1990a.

. O normal e o patológico. Rio de Janeiro: Forense Universitária, 1990b.

. Meio e normas do homem no trabalho. Proposições, Campinas, v. 12, n. 2-3, p. 109-121, 2001.

CLOT, Y. A função psicológica do trabalho. Petrópolis: Vozes, 2006.

CRU, D. As regras de ofício. Plaisir et souffrance dans le travail. Séminaire interdisciplinaire de psychopatologie du travail, 2 v. Paris: Éditions de l'Association pour l'ouverture du Champ D'investigation Psychopathologique (AOCIP), 1988.

CURIE, J. et al. Proposition méthodologique pour la description du système des activités. Le Travail Humain, Paris, v. 53, n. 2, p. 103-118, 1990.

CYRINO, R. Trabalho, temporalidade e representações sociais de gênero: uma análise da articulação entre o trabalho doméstico e assalariado. Sociologias, Porto Alegre, v. 11, n. 21, p. 66-92, 2009.

DANIELLOU, F. (Org.). A ergonomia em busca de seus princípios: debates epistemológicos. São Paulo: Editora Edgard Blücher, 2004. 
DEDECCA, C. S. Tempo, trabalho e gênero. In: COSTA, A. A. et al. (Org.). Reconfiguração das relações de gênero no trabalho. São Paulo: CUT Brasil, 2004. p. 21-51.

DEDECCA, C. S.; RIBEIRO, C. S. M. F.; ISHII, F. J. Gênero e jornada de trabalho: análise das relações entre mercado de trabalho e família. Trabalho, Educação e Saúde, Rio de Janeiro, v. 7, n. 1, p. 65-90, 2009.

DEJOURS, C. Inteligência operária e organização do trabalho: a propósito do modelo japonês de produção. In: HIRATA, H. (Org.). Sobre o "modelo" japonês: automatização, novas formas de organização e de relações de trabalho. São Paulo: Edusp, 1993. p. 281309.

DEJOURS, C.; ABDOUCHELI, E. Itinerário teórico em psicopatologia do trabalho. In: DEJOURS, C.; ABDOUCHELI, E.; JAYET, C. (Org.). Psicodinâmica do trabalho: contribuições da escola dejouriana à análise da relação prazer, sofrimento e trabalho. São Paulo: Atlas, 1994. p. 119-45.

ELIAS, N. O processo civilizador. Rio de Janeiro: Jorge Zahar, 1994a. v. 1.

A sociedade dos indivíduos: Rio de Janeiro: Jorge Zahar, 1994b.

1998. Sobre o tempo. Rio de Janeiro: Jorge Zahar, . Introdução à sociologia. Lisboa: Edições 70, 2008.

FERREIRA, J. P. A restituição dos resultados de pesquisa: em busca do diálogo entre pesquisadores e trabalhadores de enfermagem. 2009. 185 f. Dissertação (Mestrado em Saúde Pública)-Escola Nacional de Saúde Pública, Fundação Oswaldo Cruz, Rio de Janeiro, 2009.

FISCHER, F. M.; MORENO, C. R. C.; ROTENBERG, L. (Org.). Trabalho em turnos e noturno na sociedade 24 horas. Rio de Janeiro: Atheneu, 2004.

GERNET, I. Les relations entre santé et travail du point de vue de la psychodynamique du travail. Mouvements, Paris, v. 2, n. 58, p. 79-84, 2009.

GOMES, L.; BRITO, J. Desafios e possibilidades ao trabalho docente e à sua relação com a saúde. Estudos e Pesquisas em Psicologia, Rio de Janeiro, v. 6, n. 1, p. 1-14, 2006.

GUÉRIN, F. et al. Compreender o trabalho para transformá-lo: a prática da ergonomia. São Paulo: Edgar Blücher, 2001.

HIRATA, H. Nova divisão sexual do trabalho? Um olhar voltado para a empresa e a sociedade. São Paulo: Boitempo Editorial, 2002.

HIRATA, H.; KERGOAT, D. Rapports sociaux de sexe et psychopathologie du travail. In: DEJOURS, C. (sous le direction de). Plaisir et souffrance dans le travail. Paris: Éditions de l'Association pour l'ouverture du Champ
D’investigation Psychopathologique (AOCIP), 1988. p. 131-163.

. A divisão sexual revisitada. In: MARUANI, M.; HIRATA, H. (Org.). As novas fronteiras da desigualdade: homens e mulheres no mercado de trabalho. São Paulo: Senac, 2003. p. 111-124.

. Novas configurações da divisão sexual do trabalho. Cadernos de Pesquisa, São Paulo, v. 37, n. 132, p. 595-609, 2007.

. Divisão sexual do trabalho profissional e doméstico: Brasil, França, Japão. In: COSTA, A. O. et al. (Org.). Mercado de trabalho e gênero - comparações internacionais. Rio de Janeiro: Editora Fundação Getúlio Vargas, 2008. p. 263-178.

HUBAULT, F. L'Aproche ergonomique des questions santé/travail. Mouvements, Paris, v. 2, n. 58, p. 97-102, 2009.

JURCZYK, K. Time in women's everyday lives: between self-determination and conflicting demands. Time \& Society, Londres, v. 7, n. 2-3, p. 283-308, 1998.

KERGOAT, D. Em defesa de uma sociologia das relações sociais. Da análise crítica das categorias dominantes à elaboração de uma nova conceituação. In: KARTCHEVSKY-BULPORT, A. (Org.). O sexo do trabalho. Rio de Janeiro: Paz e Terra, 1986. p. 79-93.

. Relações sociais de sexo e divisão sexual do trabalho. In: LOPES, M. J. M.; MEYER, D. E.; WALDOW, V. R. (Org.) Gênero e saúde. Porto Alegre: Artes Médicas, 1996. p. 7-18.

. Divisão sexual do trabalho e relações sexuais de sexo. In: HIRATA, H. et al. (Org.). Dicionário crítico do feminismo. São Paulo: Unesp, 2009. p. 67-75.

LANCMAN, S.; SZNELWAR, L. I. (Org.). Christophe Dejours: da psicopatologia à psicodinâmica do trabalho. Rio de Janeiro/Brasília: Fiocruz/Paralelo 15, 2004.

LAURELL, A. C.; NORIEGA, M. Processo de produção e saúde. São Paulo: Hucitec, 1989.

LE BLANC, G. La vie humaine: anthropologie et biologie chez Georges Canguilhem. Paris: PUF, 2002.

MARCONDES, W. B. et al. O peso do trabalho "leve" feminino à saúde. São Paulo em Perspectiva, São Paulo, v. 17, n. 2, p. 91-101, 2003.

MASSON, L. P. A dimensão relacional do trabalho de auxiliares de enfermagem de uma unidade neonatal: uma análise do ponto de vista da atividade. 2007. 236 f. Dissertação (Mestrado em Saúde Pública)-Escola Nacional de Saúde Pública, Fundação Oswaldo Cruz, Rio de Janeiro, 2007.

MASSON, L. P.; BRITO, J.; ATHAYDE, M. Dimensão relacional da atividade de cuidado e condições de trabalho de auxiliares de enfermagem em uma Unidade Neonatal. Physis, Rio de Janeiro, v. 21, n. 3, p. 879-898, 2011. 
MESSING, K. La santé des travailleuses. La science est-elle aveugle? Montréal-Toulouse: Éditions du remueménage-Octares, 1998.

MESSING, K.; ÖSTLIN, P. Gender equality, work and health: A review of the evidence. Genebra: Work Health Organization, 2006.

MESSING, K.; SEIFERT, A. M.; ESCALONA, E. The 120-S Minute: using analysis of work activity to prevent psychological distress among elementary school teachers. Journal of Occupational Health Psychology, Washington, v. 2, n. 1, p. 45-62, 1997.

MINAYO-GOMEZ, C.; LACAZ, F. A. C. Saúde do trabalhador: novas-velhas questões. Revista Ciência e Saúde Coletiva, Rio de Janeiro, v. 10, n. 4, p. 797-807, 2005.

MOLINIER, P. Psychodynamique du travail et identité sexuelle [these]. Paris: Conservatoire National des Arts et Metiers, 1995.

NEVES, M. Y.; SELIGMANN-SILVA, E. Trabalho docente: precarização e feminização de uma prática profissional. In: BRITO, J. et al. (Org.). Trabalhar na escola? "Só inventando o prazer". Rio de Janeiro: Ipub/ Cuca, 2001. p. 23-5.

. A dor e a delícia de ser (estar) professora: trabalho docente e saúde mental. Estudos e Pesquisas em Psicologia, Rio de Janeiro, v. 6, n. 1, p. 63-74, 2006.

NEVES, M. Y. et al. Relações sociais de gênero e divisão sexual do trabalho: uma convocação teóricoanalítica para estudos sobre a saúde das trabalhadoras da educação. In: MINAYO-GOMEZ, C.; MACHADO, J. M. H.; PENA, P. G. L. (Org.). Saúde do trabalhador na sociedade brasileira contemporânea. Rio de Janeiro: Fiocruz, 2011. p. 495-516.

NOGUEIRA, C. M. O trabalho duplicado: a divisão sexual no trabalho e na reprodução - um estudo das trabalhadoras do telemarketing. São Paulo: Expressão Popular, 2006.

ODDONE, I.; RE, R.; BRIANT, G. Redecouvrir l'expérience ouvrière: vers une autre psychologie du travail? Paris: Messidor, Éditions Sociales, 1981.

OLIVEIRA, S. Relação de serviço, telemarketing e saúde: algumas aproximações. In: MINAYO-GOMEZ, C.; MACHADO, J. M. H.; PENA, P. G. L. (Org.). Saúde do trabalhador na sociedade brasileira contemporânea. Rio de Janeiro: Fiocruz, 2011. p. 517-539.

PACHECO, V. G. Gênero, saúde e trabalho: fatores que interagem no desenvolvimento de LER em trabalhadores telefônicos. 2002. 236 f. Dissertação (Mestrado em Psicologia Social)-Faculdade de Filosofia e Ciências Humanas, Universidade Federal de Minas Gerais, Belo Horizonte, 2002.

PINHEIRO, L. et al. Retrato das desigualdades de gênero e raça. Brasília: Ipea; SPM; Unifem, 2008.

RAMMINGER, T. Cada Caps é um Caps: a importância dos saberes investidos na atividade para o desenvolvimento do trabalho em saúde mental. 2009. 226 f. Tese (Doutorado em Saúde Pública)-Escola Nacional de Saúde Pública, Fundação Oswaldo Cruz, Rio de Janeiro, 2009.

RIBEIRO-SILVA. O dia de quem trabalha à noite: reflexões sobre o cotidiano de profissionais de enfermagem que trabalham à noite em um hospital público no Rio de Janeiro. Monografia (Bacharelado em Psicologia)-Universidade do Estado do Rio de Janeiro, Rio de Janeiro, Brasil, 2006.

RIBEIRO-SILVA, F; ROTENBERG, L. Tiempo para si y tiempo para otros en mujeres. In: CONGRESO INTERNACIONAL MUJER, TRABAJO Y SALUD, 5., 2008, Zacatecas, México. Anales... Zacatecas: Universidad Autônoma de Zacatecas, 2008. p. 176.

ROCHA, L. E. et al. Fatores de risco para sintomas osteomusculares entre operadores de uma central de atendimento telefônico de um banco localizado em São Paulo. Boletim da Saúde, Porto Alegre, v. 20, n. 1, p. 119-128, 2006.

ROTENBERG, L. Relações de gênero e gestão dos tempos - a articulação entre o trabalho profissional e doméstico em equipes de enfermagem no Brasil. Laboreal, Porto, v. 8, n. 1, p. 72-84, 2012.

ROTENBERG, L. et al. Sono, cotidiano e vivências de quem troca a noite pelo dia. Cadernos de Saúde Pública, Rio de Janeiro, v. 17, n. 3, p. 639-649, 2001.

ROTENBERG, L. et al. Housework and recovery from work among nursing teams: a gender view. New Solutions, v. 20, n. 4, p. 497-510, 2010.

SCHWARTZ, Y. A comunidade científica ampliada e o regime de produção de saberes. Trabalho \& Educação, Belo Horizonte, v. 7, p. 38-47, 2000.

. A abordagem do trabalho reconfigura nossa relação com os saberes acadêmicos: as antecipações do trabalho. In: SOUZA-E-SILVA, M. C. P.; FAÏTA, D. (Org.). Linguagem e trabalho: construção de objetos de análises no Brasil e na França. São Paulo: Cortez, 2002. p. 109-126.

SCHWARTZ, Y.; DURRIVE, L. (Org.). Trabalho e ergologia: conversas sobre a atividade humana. Niterói: EdUFF, 2010.

SEGNINI, L. R. P. Relações de gênero e racionalidade do trabalho em serviços de atendimento a distância. In: SALERNO, M. (Org.). Relação de serviço: produção e avaliação. São Paulo: Senac, 2001. p. 151-183.

SILVA-COSTA, A. et al. Relationship between sleeping on the night shift and recovery from work among nursing workers - the influence of domestic work. Journal of Advanced Nursing, v. 67, n. 5, p. 972-981, 2011.

SOARES, R. E. S. Tempo, trabalho e modo de vida: um estudo de caso entre profissionais de enfermagem. 2005, 81 f. Dissertação (Mestrado em Antropologia)Departamento de Antropologia, Universidade Federal Fluminense, Niterói, 2005. 
SORJ, B. Sociologia e trabalho: mutações, encontros e desencontros. Revista Brasileira de Ciências Sociais, São Paulo, v. 15, n. 43, p. 25-34, 2000.

SOUZA, A. M. R. Z. Atividade de cuidados em UTI Neonatal: uma análise das relações entre trabalho de enfermagem e a saúde. 2010. 173 f. Dissertação (Mestrado em Saúde Pública)-Escola Nacional de Saúde Pública, Fundação Oswaldo Cruz, Rio de Janeiro, 2010.
TABBONI, S. The idea of social time in Norbert Elias. Time \& Society, Londres, v. 10, n. 1, p. 5-27, 2001.

TEIGER, C. Lapproche ergonomique: du travail humain à l'activité des hommes et des femmes au travail.

Education Permanente, Paris, v. 116, n. 3, p. 71-96, 1993.

WISNER, A. A inteligência no trabalho: textos selecionados de ergonomia. São Paulo: Fundacentro, 1994. 